\title{
УДК 633.88.577.16 \\ СОДЕРЖАНИЕ И ДИНАМИКА НАКОПЛЕНИЯ АСКОРБИНОВОЙ КИСЛОТЫ В ПЛОДАХ ROSA CANINA L.
}

\author{
(C) А.Р. Новрузов
}

\author{
Азербайджанский государственный аграрный университет, пр. Ататюрка, \\ 262, Гянджа, AZ2000 (Азербайджан), e-mail: eldar_novruzov@yahoo.co.uk
}

\begin{abstract}
При изучении содержания и динамики накопления аскорбиновой кислоты в плодах Rosa canina L. установлено, что Нахчыванская популяция характеризуется высоким содержанием аскорбиновой кислоты. Количество аскорбиновой кислоты зависит от видовой особенности, местопроизрастания, высоты местности, механического состава почвы, климатических условий вегетационного периода и возраста растений. Наибольшее количество аскорбиновой кислоты накапливается в плодах 4-5 летних стволиков в фазе технической зрелости.

Ключевые слова: содержание, динамика, витамин C, Rosa L.
\end{abstract}

\section{введение}

Шиповники большое значение имеют в жизни человека. Они используются как сырье для изготовления лекарств, вин, эфирного масла, витаминов, уксуса, дубильного экстракта, водных настоев и др. Целебные свойства шиповника известны давно. Цветы и плоды шиповника использовались еще в XVI и XVII вв. как средство, излечивающее цингу и другие болезни. Маслом из семян шиповника лечили ожоги, катаральное воспаление слизистых оболочек горла, простудные заболевания. Широкое и почти универсальное применение шиповника как лекарственного средства, начатое с XVI в., только в XX столетии получило научное объяснение, когда выяснилось, что шиповники являются естественным концентратом поливитаминов [1].

Среди всех плодово-ягодных растений, плоды шиповника являются рекордным носителем витамина $\mathrm{C}[2,3]$. Аскорбиновой кислоты в плодах шиповника в 10 раз больше, чем в ягодах смородины, в 50 раз чем в лимоне, в 100 раз - чем в яблоках [4].

Впервые на большое содержание витамина С (аскорбиновой кислоты) в шиповниках указали в 1931 г. Галн [5], С. Тильманс и др. [6], которые из плодов получили кристаллический препарат аскорбиновой кислоты. В 1934 г. Н.Н. Иванов и др. [7] также выделили из плодов шиповника в чистом виде витамин С.

Дальнейшие исследования показали, что плоды некоторых видов шиповника, широко распространенные на Украине, в России, Средней Азии, относящиеся к секции Cinnaтотеае DC (роза коричная, p. иглистая, p. даурская, p. Уэбба, p. Федченко, p. Беггера, p. Альберта, p. морщинистая и др.) наиболее богаты витамином C [8-14]. Например, содержание аскорбиновой кислоты в р. коричной и р. Беггера достигает 14000 и 19000 мг \% (соответственно) на сухой вес мякоти плода [15]. Места произрастания и почвенно-климатические условия растений очень сильно влияют на содержание аскорбиновой кислоты в плодах. Например, концентрации витамина $\mathrm{C}$ у плодов $R$. cinnaтотеа L, произрастающие в разных местах изменяется от 1444 до 2038 мг \%; плоды вида R. pendulina L. выращенный из семян в Ботаническом саду Львовского Государственного Университета, накапливают 2551 мг \%, а на субальпийских лугах 2889 мг \% витамина С. В 37 образцах этого вида собранных из различных мест произрастания содержание аскорбиновой кислоты колеблется от 900 до 2800 мг \% [1].

Большая амплитуда колебания содержания витамина $\mathrm{C}$, по нашему мнению, зависит не только от вида и географического места произрастания, но и от времени сбора плодов, фиксации материала, а также метода исследования. Многие авторы не указывают время сбора, место произрастания, состояние плодов и показы-

Новрузов Амил Рустам огль - старший преподаватель,

e-mail: latafat_shamsizade@mail.ru вают содержание аскорбиновой кислоты в плодовой мякоти шиповника в процентах, без учета семян и др. 
Имеющие в литературе данные о содержании и динамике накопления аскорбиновой кислоты в плодах шиповника разноречивы $[15,16]$ изложенного следует, что по изучению витамина С, особенно по содержанию и накоплению этого витамина в плодах шиповника сделано немало. Но имеется еще много вопросов, не освещенных в литературе, для решения которых необходимы дальнейшие исследовательские работы. Например, таких как изучение аскорбиновой кислоты в плодах шиповника в зависимости от фазы созревания плодов, возраста стволиков, места расположения ветвей на стволике, почвы, метеорологических условий года и др. Изучение динамики накопления аскорбиновой кислоты в процессе роста и развития, особенно в фазе созревания, очень важно для определения времени сбора плодов шиповника. От этого зависит качество и количество заготавливаемых плодов. Продолжая изучение шиповников, распространенных в Нахчыванской АР $[17,18]$, мы поставили перед собой цель изучить накопления витамина С во время роста и развития плодов Rosa canina $\mathrm{L}$.

\section{Экспериментальная часть}

Объектом исследования были плоды вида Rosa canina L. наиболее широко распространенные и имеющие большой эксплуатационный запас.

Образцы для анализа брали из 20-25 растений, со всех экспозиций. Плоды отбирали по стандартной величине, форме, окраске, не поврежденные механически, вредителями и болезнями. Динамику накопления аскорбиновой кислоты изучали на одних и тех же растениях, в одно и то же время суток. С целью выяснения изменения количественного содержания витамина С плоды собирали в четырех фазах: завязи, в незрелых, но вполне сформированных достигающих примерно половины свойственного им размера, зеленых, покрасневших, зрелых и перезрелых плодах. Зрелые плоды исследовали в различных стадиях созревания - технически зрелый, биологически зрелый и перезрелый. Содержание аскорбиновой кислоты определяли в свежесобранных материалах. Подготовку сырья к анализу проводили по общепринятым методом [19]. Содержание аскорбиновой кислоты определяли фотоколориметрическим методом, описанным в ГФ ХІ для ФС «Плоды шиповника» [20].

Материалом исследования были плоды шиповника Rosa canina L.coбранные в 2010-2011 гг. в селениях Тананам, Карабаглар, Бузгов, Биченак, Насырваз, из пяти районов Нахчыванской АР (Шарурском, Кенгерлинском, Шахбузском, Джульфииском, Ордубадском), для динамики накопления витамина С, изучали плоды из урочища Шамдин, Кенгерлинского района и поймах реки Кюкючай Шахбузского района.

Климат Нахчыванской АР умеренно континентальный, со средней температурой в июле от + 12 до $20{ }^{\circ} \mathrm{C}$, в январе - от 4 до $8{ }^{\circ} \mathrm{C}$, в целом характеризуется обилием тепла и сухостью. Среднегодовое количество осадков в низменностях составляет 300-500 мм, в горах - 600-800 мм [21].

\section{Результаты и обсуждение}

Результаты анализа, проведенные в 2010 г., показали, что в зависимости от местопроизрастания, содержание аскорбиновой кислоты в плодах R. canina L. колеблется от 701 мг \% до 987 мг \% на сырой вес, а в 2011 г. от 765 до 968 мг \%. Содержание аскорбиновой кислоты в плодах, также зависит от индивидуального состояния растений. Например, в собранных образцах из окрестности Тананам, Шарурского района, произрастающие в одинаковых условиях, содержание аскорбиновой кислоты в плодах изменяется от 765 до 991 мг\%.

Из таблицы следует, что содержание аскорбиновой кислоты в плодах увеличивается с повышением высоты местности. Плоды, произрастающие на высоте 650 м н.ур.м. (с. Карабаглар), содержат 701 мг \%, а плоды, произрастающие на высоте 1600 м над ур.м. (с. Биченак) - 916 мг \% аскорбиновой кислоты. Очевидно, что по мере подъема в горы на увеличение содержания витамина С, оказывает влияние понижение температуры и повышения ультрафиолетовой радиации, так как в горах радиации больше, чем в низменности.

Известно, что по содержанию аскорбиновой кислоты различные части плодов и ягод различаются $[22,23]$. Наши исследования в плодах шиповника показали, что аскорбиновая кислота распределяется неравномерно. 
Таблица 1. Изменение содержание аскорбиновой кислоты в плодах R. canina L. в зависимости от местопроизрастания (мг \% на сырую массу)

\begin{tabular}{c|c|c|c}
\hline Время сбора & Количество образцов, шт. & Место произрастания & Количество витамина С \\
\hline 07.09 .2010 & 5 & с. Тананам, Шарурского района & $765-991$ \\
10.09 .2011 & 6 & с. Тананам, Шарурского района & $817-985$ \\
10.09 .2010 & 6 & с. Карабаглар, Кенгерлинского района & $701-989$ \\
15.09 .2011 & 5 & с. Карабаглар, Кенгерлинского района & $768-835$ \\
12.09 .2010 & 6 & с. Ашагы - Бузгов, Нахчыванского района & $817-1031$ \\
11.09 .2011 & 6 & с. Ашагы - Бузгов, Нахчыванского района & $801-987$ \\
14.09 .2010 & 6 & с. Бичанак, Шахбузского района & $916-1102$ \\
13.09 .2011 & 6 & с. Бичанак, Шахбузского района & $967-1135$ \\
13.09 .2010 & 5 & с. Бадамлы, Шахбузского района & $835-957$ \\
15.09 .2011 & 5 & с. Бадамлы, Шахбузского района & $857-969$ \\
08.09 .2010 & 4 & с. Газанчы, Джулфинского района & $957-1058$ \\
14.09 .2011 & 5 & с. Газанчы, Джулфинского района & $968-1101$ \\
16.09 .2010 & 6 & с. Насирваз, Ордубадского района & $987-1125$ \\
17.09 .2011 & 5 & с. Насирваз, Ордубадского района & $965-1102$ \\
\hline
\end{tabular}

При пересчете весовых отношений различных частей к общей массе плода получается, что основное количество витамина С сосредоточено в мякоти - основной части плода. Аналогичное распределение аскорбиновой кислоты в плодах наблюдается почти во всех плодово-ягодных растениях [24]. Большее количество аскорбиновой кислоты содержится также в соке, а наименьшее - в семенах.

Таблица 2. Распределение аскорбиновой кислоты в отдельных частях плодов шиповника

\begin{tabular}{c|c}
\hline Анализируемая & Содержание, мг \% на \\
часть плода & сырую массу \\
\hline Мякоть & 985,7 \\
Сок & 843,6 \\
Семена & 87,5 \\
\hline
\end{tabular}

Как известно, различные части одного и того же растения отличаются как по содержанию воды, минеральных веществ, так и по содержанию органических веществ. Зависит это от возраста, освещения растений, микроклимата и других факторов. Проведенные нами исследования по содержанию аскорбиновой кислоты в плодах шиповника показало, что содержание аскорбиновой кислоты в плодах имеет определенную зависимость от возраста стволиков кустов шиповника (табл. 3). Из таблицы следует, что наименьшее количество витамина С отмечено в плодах собранные с 2-летних стволиков, а затем оно постепенно повышается, а начиная с 5 лет отмечается некоторое понижение. Очень редко отмечено повышение содержание аскорбиновой кислоты у 6-летних стволиков. Однако 6-летние стволики мало плодоносят, остаются в зарослях мало, поэтому они существенного значения не имеют. Таким образом, установили, что большее накопление аскорбиновой кислоты в плодах $R$. canina L. наступает в 4-5-летнем возрасте стволиков. Изучения урожайности, средней массы плодов и содержание аскорбиновой кислоты показывают, что все они находятся в зависимости от возраста стволиков. В 4-5-летнем возрасте стволиков у R. canina L. наблюдается высокое плодоношение и большее накопление аскорбиновой кислоты, а естественное отмирание стволиков происходит в 5-6 летнем возрасте.

В процессе работы 2009-2011 гг. были еще проведены анализы плодов, собранные из боковых побегов, разветвленные в нижние, средние и верхние части стволиков $R$. canina, в возрасте 3-5 лет. Данные приведены на таблице 4.

Как следует из данных, наибольшее содержание витамина С наблюдается в плодах, собранных со средних ветвей, затем - из нижних ветвей и наименьшее - из верхних ветвей.

Для установления влияния механического состава почвы на накопления аскорбиновой кислоты сделаны анализы образцов плодов собранные в 2011 г., из поймы р. Джагричая. Результаты анализов представлены в таблице 5 .

Таблица 3. Содержание аскорбиновой кислоты в плодах $R$. canina L. в зависимости от возраста стволиков, мг \% на сырую массу

\begin{tabular}{c|c|c|c}
\hline \multirow{2}{*}{ Возраст стволиков } & \multicolumn{2}{|c|}{ Урочища Шамдин } & Пойма реки. Кюкючай \\
\cline { 2 - 4 } & 2010 г. & 2011 г. & 2010 г. \\
\hline 2 & 789 & 802 & 1062 \\
3 & 896 & 917 & 1135 \\
4 & 935 & 965 & 1062 \\
6 & 909 & 903 & 1035 \\
\hline
\end{tabular}


Таблица 4. Содержание аскорбиновой кислоты в плодах $R$. canina L. в зависимости от расположения ветвей в стволике, мГ \% на сырой вес

\begin{tabular}{c|c|c|c}
\hline \multirow{2}{*}{ Ярус } & \multicolumn{2}{|c|}{ Урочища Шамдин } & Пойма р. Кюкючай \\
\cline { 2 - 4 } & 2010 г & 2011 г & 2010 г \\
\hline Нижний & 835 & 846 & 902 \\
Средний & 917 & 927 & 1031 \\
Верхний & 733 & 755 & 883 \\
\hline
\end{tabular}

Таблица 5. Содержание аскорбиновой кислоты в плодах R. canina в зависимости от механического состава почвы (мг \% на сухую массу мякоти)

\begin{tabular}{|c|c|c|c|}
\hline \multirow{2}{*}{$\begin{array}{c}\text { Механический } \\
\text { состав почвы }\end{array}$} & \multirow{2}{*}{$\begin{array}{c}\text { Количество } \\
\text { анализов }\end{array}$} & \multicolumn{2}{|c|}{ Содержание аскорбиновой кислоты (мг\%) } \\
\hline & & Максимальное & Минимальное \\
\hline Свежая суглинистая & 7 & 985 & 691 \\
\hline Супесчаная & 9 & 765 & 459 \\
\hline Песчаная & 7 & 717 & 403 \\
\hline
\end{tabular}

Как следует из таблицы 5, наибольшее содержание аскорбиновой кислоты в плодах наблюдается у шиповника, растущего на свежих суглинистых почвах, несколько меньше - на супесчаных и наименьшее - на песчаных почвах.

Данные анализов по содержанию витамина C в спелых плодах $R$. canina L., собранных из пробных площадей в урочище Шамдин, приведены в таблице 6. Высокое содержание аскорбиновой кислоты было в 2010 г. (985 мг\%), 2009 г. (869 мг\%), а наименьшее - в 2011 г. (765 мг\%). Эти годы по метеорологическим условиям характеризуются как засушливые. В течение мая и июня относительная влажность была $30 \%$, осадков в 2009 г. - 65 мм, а в 2011 г. - 145 мм. Средняя месячная температура в мае 2009 г. составляла $+16,3{ }^{\circ} \mathrm{C}$, а в 2011 г. $+9,9^{\circ} \mathrm{C}$, май 2009 г. был сухим и жарким, а май 2011 г. - сухим и холодным. Весеннелетний период 2011 г. по сравнению с 2009 г. был неблагоприятным, этим и объясняется несколько пониженное содержание витамина С в плодах шиповника в 2011 г.

Нами также проведены анализы по изучению динамики накопления аскорбиновой кислоты в плодах вида R. canina L.по мере роста и развития плода. Результаты анализа представлены в таблице 7.

Как следует из таблицы 7, по мере созревания плодов непрерывно увеличивается содержание витамина С, достигая максимума в фазе вполне зрелых (но не перезрелых) плодах, что полностью согласуются с данными предыдущих исследователей $[9,11]$.

Исследования изменения содержания аскорбиновой кислоты в течение дня показало, что оно подвержено значительному колебанию. Результаты анализа отражены в таблице 8.

Таблица 6. Влияние климатических условий на накопление аскорбиновой кислоты в плодах шиповника

\begin{tabular}{c|c}
\hline Годы & $\begin{array}{c}\text { Содержание } \\
\text { мг на сырую массу }\end{array}$ \\
\hline 2009 & 869 \\
2010 & 985 \\
2011 & 765 \\
\hline
\end{tabular}

Таблица 8. Суточное изменение содержания аскорбиновой кислоты в плодах шиповника

\begin{tabular}{c|c}
\hline Время взятия проб, ч & $\begin{array}{c}\text { Содержание, мг \% на } \\
\text { сырую массу }\end{array}$ \\
\hline 7 & 557 \\
10 & 785 \\
13 & 859 \\
16 & 840 \\
19 & 660 \\
\hline
\end{tabular}

Таблица 7. Изменение содержание аскорбиновой кислоты в плодах $R$. canina L. в процессе роста и развития плода (мг \% на сырой вес)

\begin{tabular}{l|c}
\hline \multicolumn{1}{c|}{ Стадия развития } & Содержание \\
\hline Завязь (через 15 дней) & 317 \\
Плоды зеленые, вполне сформирован- & 538 \\
ные (25.07.2010) & \\
Плоды желто-зеленые (04.08.2010) & 749 \\
Плоды желто-красные (15.08.2010) & 857 \\
Плоды красные 25.08.2010 & 917 \\
Плоды красные 05.09.2010 & 924 \\
Плоды красные 15.09.2010 & 910 \\
Плоды красные (перезрелые) 15.10.2010 & 865
\end{tabular}

Из таблицы 8 следует, что образование и накопление аскорбиновой кислоты в плодах шиповника подчинены определенной закономерности. Количество аскорбиновой кислоты увеличивается с 7 ч утра и в 13 ч доходит до максимума. Во второй половине дня количество аскорбиновой кислоты постепенно уменьшается. 


\section{Выводы}

1. Установлено, что плоды вида Rosa canina L. Нахчыванской популяции, характеризуются высоким содержанием аскорбиновой кислоты, ее содержание в период вегетации зависит от местопроизрастания, высоты местности и климатических условий.

2. Аскорбиновая кислота в отдельных частях плода распределяется неравномерно. Наибольшое количество накапливается в мякоти плода - 985,7 мг\%, а наименьшее в семенах - 87,5 мг \%.

3. Выявлено, что на содержание аскорбиновой кислоты влияют возраст растений и отдельных стволиков, а также положение плода на боковых ветвях. Наибольшее количество аскорбиновой кислоты накапливается в плодах 4-5-летних стволиков среднего яруса.

4. По мере роста и развития плодов содержание аскорбиновой кислоты изменяется. Большое количество накапливается в период технической зрелости и держится до биологической зрелости плодов, а в перезрелых плодах содержание немного снижается.

5. Установлено, что содержание аскорбиновой кислоты в плодах шиповника в течение дня подвергается определенному изменению. Начиная с утренних часов содержание аскорбиновой кислоты, возрастает, и в 13 ч дня доходит до максимума - 859 мг\% (на сырой вес), а к полудню постепенно уменьшается и в 19 ч доходит до 660 мг\%.

\section{Список литературы}

1. Хржановский В.Г. Розы (филогения и систематика, спонтанные виды Европейской Части СССР, Крыма и Кавказа, опыт и перспективы использования. М., 1958. 497 с.

2. Игнатьев Б.Д. Шиповник и его использование. Новосибирск, 1946. 322 с.

3. Лысоконь П.Ф. Розы (шиповники) и их использование // Изв. АН БССР. 1949. №2. С. 231-256.

4. Рожков М.И., Смирнов Н.Е. Витаминные растения. М., 1956. 196 с.

5. Tilmans S., Hirsch P., Vaubel R. // Zeitschr. f. Untersuch des Lebensmitter. 1933. Vol. 65. Pp. 45-47.

6. Haln F. // Itschr. F. Untersuch. Des Lebensmi Helen. 1931. Vol. 61. Pp. 4-21.

7. Иванов Н.Н., Марга В.Я., Онохова Н.П. Опыт выделения антицынготного витамина из шиповника // Проблема витаминов: Сб. раб. ВИР. Л., 1934. №1. С. 110-115.

8. Кочкарева Т.Ф., Трофимова Е.П. Шиповники Таджикистана и их витаминная активность // Изв. АН ТаджССР: отд. биол. наук., 1967. №1. С. 17-28.

9. Мухамеджанов И. Динамика содержания витаминов в плодах некоторых видов шиповника долины р. Пекем // Матер. по физиол. и эколог. растений Средней Азии. Ташкент, 1966. С. 110-119.

10. Буткене 3.П. Биологическая и биохимическая характеристика шиповника морщинистого // Тр. АН Литов. CCР, cep. С. 1974. №2. С. 31-36.

11. Панков Ю.А., Гладченко В.П. Содержание и динамика накопления аскорбиновой кислоты у видов шиповника советского Дальнего Востока // Растительные ресурсы. 1975, Т. 11, вып. 3. С. 394-398.

12. Шнякина Г.П., Малыгина Э.П. Витамины и фенольные соединения в плодах дальневосточных видов шиповника // Растительные ресурсы. 1975, Т. 11, вып. 3. С. 390-394.

13. Алексеев Б.Д. Химическое изучение шиповников Дагестана // Растительные ресурсы. 1981. Т. 7, вып. 4. C. 557-564.

14. Krzaczek T., Krzaczek W., Chybowski J. Badania Zawartosci Wiitaminy C «Owacach» roz Lubelszyzny // Ann. UMCS C. 1970, Vol. 25. Pp. 307-321.

15. Розанова М.А. Влияние климатических и почвенных условий на содержание аскорбиновой кислоты в шиповнике // Витамины в теории и практике. М., 1954. Т. 5. С. 96-101.

16. Розанова М.А. Изменчивость аскорбиновой кислоты в роде Rosa // Бюллетень Московского общества испытателей природы: Отд. биол. 1946. Т. 51, вып. 4/5. С. 102-113.

17. Лысконь П.Ф. Динамика витамина С в плодах розы морщинистой (R. rugosa Thunb.) и розы даурской (R. daurica Pall.) // Изв. АН БССР, сер. биол. наук. 1958. №4. С. 501-508.

18. Новрузов А.Р., Шамсизаде Л.А. Биохимическая характеристика плодов видов шиповника произрастающие в Нахчыване // II Российский фитотерапевтический съезд. М., 2010. С. 196-199.

19. Новрузов А.Р., Шамсизаде Л.А. Антоцианы двух видов Rosa L. // Химия природных соединений. 2011. №1. С. 107.

20. Ермаков А.И., Арасимович В.В., Ярош Н.П., Перуванский Ю.В., Луковникова Г.А., Иконникова М.И. Методы биохимического исследования растений. Л., 1987. 430 с.

21. Государственная Фармакопея СССР. Вып. 2: ФС «Плоды шиповника». 11-е изд., М., 1987. С. $317-319$.

22. Егоров А.Д. Витамин С и каротин в растительности Якутии. М., 1954. 248 с.

23. Ермаков А.И., Луковникова Г.А. Влияние природных условий и приемов выращивания на содержание аскорбиновой кислоты и каротина в плодовых и овощных растениях // Витамины. 1959. №4. С. $209-216$.

Поступило в редакичию 20 февраля 2013 2. 
Novruzov A.R. CONTENTS AND DYNAMICS OF ACCUMULATION OF THE ASCORBIC ACID IN FRUITS OF ROSA CANINA L.

Azerbaijan State Agrarian University, Atatjurka ave., 262, Ganja, AZ2000 (Azerbaijan), e-mail: eldar_novruzov@yahoo.co.uk

In studying the contents and accumulation dynamics of the ascorbic acid in Rosa canina L. fruits established that Nakhchvan population is characterized by the high content of ascorbic acid. The quantity of ascorbic acid depends on specific features, habitat, altitude, the mechanical compositions of soil, climatic conditions of vegetation period and age of plants. The greatest amount of ascorbic acid accumulates in fruits of the 4-5 years old trunks in a phase of a technical maturity.

Keywords: content, dynamics, vitamin C, Rosa L.

\section{References}

1. Khrzhanovskii V.G. Rozy (filogeniia i sistematika, spontannye vidy Evropeiskoi Chasti SSSR, Kryma i Kavkaza, opyt $i$ perspektivy ispol'zovaniia. [Roses (phylogeny and systematics, spontaneous forms of the European part of the USSR, the Crimea and the Caucasus, experiences and perspectives]. Moscow, 1958, 497 p. (in Russ.).

2. Ignat'ev B.D. Shipovnik i ego ispol'zovanie. [Rosehip and its use]. Novosibirsk, 1946, 322 p. (in Russ.).

3. Lysokon' P.F. Izv. AN BSSR, 1949, no. 2, pp. 231-256. (in Russ.).

4. Rozhkov M.I., Smirnov N.E. Vitaminnye rasteniia. [Vitamin plants]. Moscow, 1956, 196 p. (in Russ.).

5. Tilmans S., Hirsch P., Vaubel R. Zeitschr. f. Untersuch des Lebensmitter, 1933, vol. 65, pp. 45-47.

6. Haln F. Itschr. F. Untersuch. Des Lebensmi Helen., 1931, vol. 61, pp. 4-21.

7. Ivanov N.N., Marga V.Ia., Onokhova N.P. Problema vitaminov: Sb. trudov VIR. [Problem vitamins: Proceedings of the VIR]. Leningrad, 1934, no. 1, pp. 110-115. (in Russ.).

8. Kochkareva T.F., Trofimova E.P. Izv. AN TadzhSSR: otd. biol. nauk, 1967, no. 1, pp. 17-28. (in Russ.).

9. Mukhamedzhanov I. Mater. po fiziol. i ekolog. rastenii Srednei Azii, [Materials on the physiology and ecology of plants of Central Asia]. Tashkent, 1966, pp. 110-119. (in Russ.).

10. Butkene Z.P. Trudy AN Litv.SSR, ser. S., 1974, no. 2, pp. 31-36. (in Russ.).

11. Pankov Iu.A., Gladchenko V.P. Rastitel'nye resursy, 1975, vol. 11, no. 3, pp. 394-398. (in Russ.).

12. Shniakina G.P., Malygina E.P. Rastitel'nye resursy, 1975, vol. 11, no. 3, pp. 390-394. (in Russ.).

13. Alekseev B.D. Rastitel'nye resursy, 1981, vol. 7, no. 4, pp. 557-564. (in Russ.).

14. Krzaczek T., Krzaczek W., Chybowski J. Ann. UMCS C., 1970, vol. 25, pp. 307-321.

15. Rozanova M.A. Vitaminy v teorii i praktike. [Vitamins in theory and practice]. Moscow, 1954, vol. 5, pp. 96-101. (in Russ.).

16. Rozanova M.A. Biulleten' Moskovskogo obshchestva ispytatelei prirody: Otd. biol., 1946, vol. 51, no. 4/5, pp. $102-113$. (in Russ.).

17. Lyskon' P.F. Izv. AN BSSR, ser. biol. nauk, 1958, no.4, pp. 501-508. (in Russ.).

18. Novruzov A.R., Shamsizade L.A. II Rossiiskii fitoterapevticheskii s"ezd. [Phytotherapeutic II Russian Congress]. Moscow, 2010, pp. 196-199. (in Russ.).

19. Novruzov A.R., Shamsizade L.A. Khimiia prirodnykh soedinenii, 2011, no. 1, p. 107. (in Russ.).

20. Ermakov A.I., Arasimovich V.V., Iarosh N.P., Peruvanskii Iu.V., Lukovnikova G.A., Ikonnikova M.I. Metody biokhimicheskogo issledovaniia rastenii. [Methods for biochemical study of plants]. Leningrad, 1987, 430 p. (in Russ.).

21. Gosudarstvennaia Farmakopeia SSSR. Vyp. 2: FS «Plody shipovnika». [State Pharmacopoeia of the USSR. Vol. 2: Pharmacopoeias article «Hips»]. 11th ed. Moscow, 1987, pp. 317-319. (in Russ.).

22. Egorov A.D. Vitamin S i karotin v rastitel'nosti Iakutii. [Vitamin C and carotene in plants of Yakutia]. Moscow, 1954, 248 p. (in Russ.).

23. Ermakov A.I., Lukovnikova G.A. Vitaminy, 1959, no. 4, pp. 209-216. (in Russ.).

Received February 20, 2013

Revised October 21, 2014 